EGU21-11063

https://doi.org/10.5194/egusphere-egu21-11063

EGU General Assembly 2021

(c) Author(s) 2022. This work is distributed under

the Creative Commons Attribution 4.0 License.

\title{
Decadal changes in the storage of anthropogenic carbon in the Atlantic Ocean
}

\author{
Verónica Caínzos ${ }^{1}$, Fiz F. Pérez ${ }^{2}$, Antón Velo ${ }^{2}$, Cristina Arumí-Planas ${ }^{1}$, Melania Cubas Armas ${ }^{1}$, \\ Daniel Santana-Toscano ${ }^{1}$, M. Dolores Pérez-Hernández ${ }^{1}$, and Alonso Hernández-Guerra ${ }^{1}$ \\ ${ }^{1}$ Unidad Océano y Clima, Instituto de Oceanografía y Cambio Global, IOCAG, Universidad de Las Palmas de Gran Canaria, \\ ULPGC, Unidad Asociada ULPGC-CSIC, Canary Islands, Spain \\ ${ }^{2}$ Instituto de Investigaciones Marinas, IIM-CSIC, 36208, Vigo, Spain
}

The Atlantic Meridional Circulation (AMOC) plays a major role in the life cycle of nutrients and chemical species in the ocean, as they are introduced into the ocean by deep water formation and resurface as part of the upwelling. We aim to obtain decadal changes in the latitudinal and vertical distribution of nutrients and carbon species in the Atlantic Ocean, using data from three inverse models carried out for the 1990-99, 2000-09 and 2010-19. We have used in situ quality-controlled data from GLODAPV2, the neural network CANYON-B for nutrients, and total alkalinity and dissolved inorganic carbon. We then compute the transport of each property, taking into account the results of mass transport balance from the inverse model for each decade. The inverse model has been applied to the whole Atlantic basin with 11 neutral density layers. With these results, we will be able to find out if the $\mathrm{CO}_{2}$ variability arises from changes in circulation or from other processes. On top of that, the availability of several zonal sections for the Atlantic enables the latitudinal division in boxes in which we may find differences in the regional anthropogenic carbon uptake. Our results will allow us to estimate how much anthropogenic carbon is being released or captured within each box, as well as the balance for other variables related to the carbon cycle. 